\title{
Restoration of fractured canines in ferrets after one-step root canal treatment
}

\author{
M. Bladowski ${ }^{1,2}$, A. Kotowicz-Gears ${ }^{2}$, J. Wojtkiewicz ${ }^{1}$ \\ ${ }^{1}$ Department of Human Physiology, Faculty of Medical Sciences, \\ University of Warmia and Mazury in Olsztyn, Warszawska 30, 10-082 Olsztyn, Poland \\ ${ }^{2}$ Research Dental Center, Szarych Szeregów 5, 10-072 Olsztyn, Poland
}

\begin{abstract}
This article describes a one-step root canal treatment and restoration of canine teeth in ferrets. Standard brass posts were used for the reconstruction of the teeth. The procedures were performed by dentists according to all rules and procedures used in root canal treatment in humans. The teeth were immediately restored anatomically. The procedures were successfully performed in four ferrets aged between 6 and 20 months of age, in three upper and one lower canines.
\end{abstract}

Key words: ferret, damage from biting, root canal treatment (RCT), vital pulpotomy, canine restoration

\section{Introduction}

Clinical experience of some surgeons shows that the dental problems of ferrets are very similar to those in cats and dogs (Bellows 2004, Tutt 2006). Tooth fractures happen often and root canal treatment can only be successful if it is undertaken within a week from the fracture. As the canine teeth are the longest and the most forward, they often become subject to the breaking off of enamel or dentin and enamel (Bellows 2004). Pulp exposure usually happens in young animals in which mineralization of the hard tissues is not complete. In such cases the only appropriate clinical solution is immediate root canal treatment and restoration of the tooth. To avoid putting the animal many times through general anaesthesia it is advisable that the root canal treatment and the restoration should be carried out in one visit. For the use of a metal or ceramic crown another session of general anaesthesia would be necessary; however - as the authors' experience shows - the chance of retaining a crown is greater than preserving the tooth when using a screw post. Dental treatment of a fractured tooth should depend on the damage and it is necessary to consider preserving the tooth, and only in the most serious cases extract it (Tutt 2006).

\section{Materials and Methods}

In a 3-year period 4 ferrets were treated due to breaking their canine teeth because of attempts to bite through the wire of their cages, which is the most common cause of tooth fractures in ferrets (Bellows 2004). 
The ferrets were: a 5-month-old male which had broken its upper left canine, a 9-month-old female which had broken its left upper canine, a 15 month old male which had broken its upper right canine and a 16-month-old male which had broken its lower left canine. All teeth were with pulp exposures.

\section{Clinical procedures}

Treatment was decided upon and took place after the clinical consultation. The animals were not given food or liquid for 6 hours before the clinical procedures. The premedication and then general anaesthesia were applied by i.m. use of: $0.2 \mathrm{ml}$ of Domitor (medetomidine hydrochloride) and Ketamin (Bioketan 10\%). Vital pulpotomy (Barańska-Gachowska 2004, Bargholz et al. 2007) was performed. The root canals were rinsed several times with sodium hypochlorite solution $(\mathrm{NaOCl})$ alternately with $0.9 \% \mathrm{NaCl}$ solution and dried with paper points. The length of the canals was measured with a frequency endometre Dat Apex (Dentsply, Barańska-Gachowska 2004). The root canals were prepared using standard files and Gates drills with stoppers (Wiggs 1991). As a lubricant 5.5\% $\mathrm{NaOCl}$ solution was used. Again, the root canals were rinsed with $\mathrm{NaOCl}$ solution alternately with $0.9 \% \mathrm{NaCl}$ solution and dried with paper points. The canals were then rinsed with $40 \%$ citric acid and dried with paper points. The root canals were filled using the technique of side condensation of cold Gutta-Percha points (Stein et al. 2004, Barańska-Gachowska 2004, Bargholz et al. 2007); as a sealant Endomethasone $\mathrm{N}_{1}$ was used. This method was considered to be the most efficient and the quickest. Another drilling with the Gates drill up to ISO-50 in 2/3 of the canals was performed. Gold plated brass screw posts - No 4XL in the lower tooth, and No $5 \mathrm{XL}$ in the upper teeth were cemented in each canal with the use of Ketac ${ }^{\mathrm{TM}} \mathrm{Cem}$ (Glass Ionomer Luting Cement, Barańska-Gachowska 2004). The lengths of the screw posts were deliberately excessive to enable further clinical procedures. After the cement had set the parts of the posts which were sticking out of the root canals were shaped with the use of diamond drills and polished with silicone rubbers so that they became similar in shape to the canine teeth, although they were slightly excluded from the occlusion. The animals were brought round by giving a subcutaneous injection of 0.1 $\mathrm{ml}$ Antisedan (antipamezole hydrochloride).

\section{Results and Discussion}

It is very important that such treatment, especially in young ferrets is performed by experienced surgeons. It is advisable to apply a "one session" treatment, using one general anaesthesia (Bellows 2004). After over a $2 \frac{1}{2}$ year observation of one of the ferrets it was found that the brass post was wearing off quicker than the enamel of the other canine. Hence it would be advisable to use a metal or ceramic crown. The described procedures are extremely rare. However, veterinary dental procedures are becoming more popular among veterinary doctors as well as dentists.

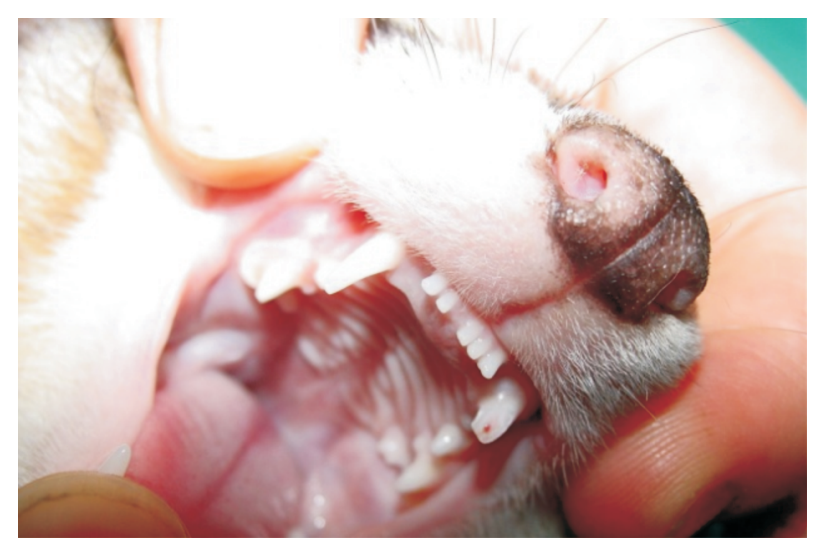

Fig. 1. Tractured left maxillary canine with pulp exposure.

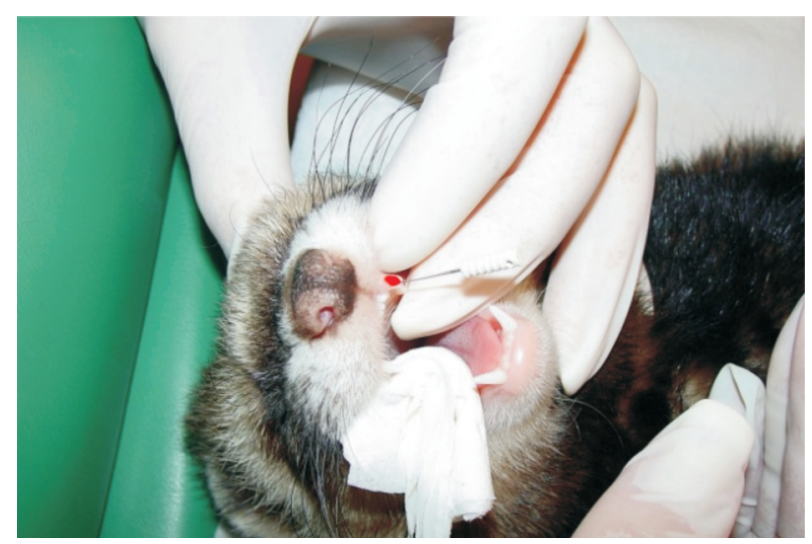

Fig. 2. Vital pulpotomy (pulp extractor ISO - 15)

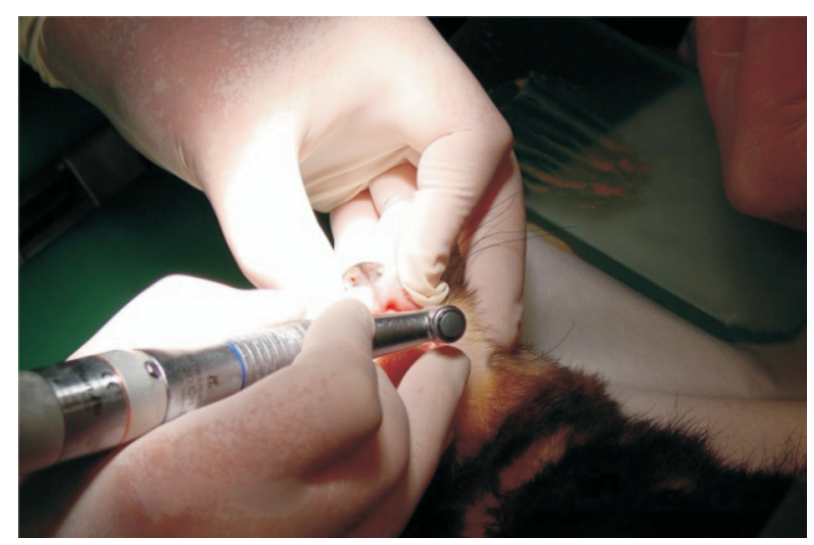

Fig. 3. Inserting the cement (Ketac ${ }^{\mathrm{TM}} \mathrm{Cem}-$ Glass Ionomer Luting Cement) with a Lentulo needle into the canal. 


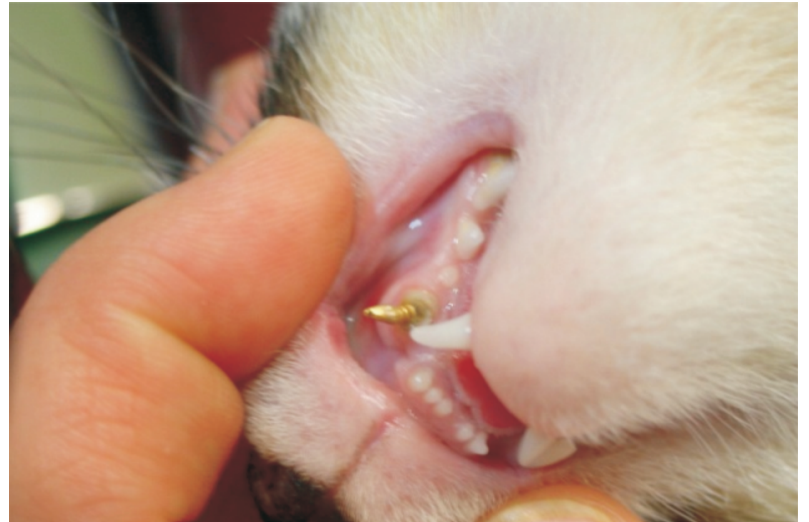

Fig. 4. Post cemented into the canal - size slightly too large - and prepared for further procedures.

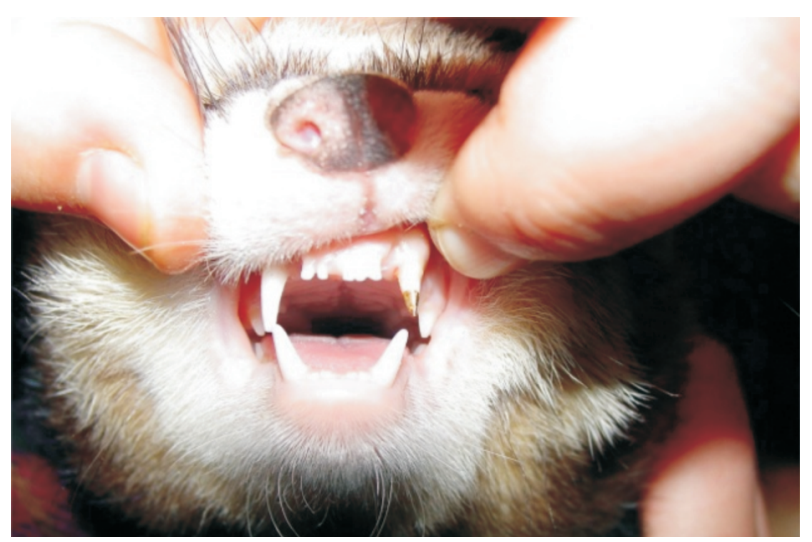

Fig. 5. Post after being given the right shape, however slightly excluded from the occlusion.

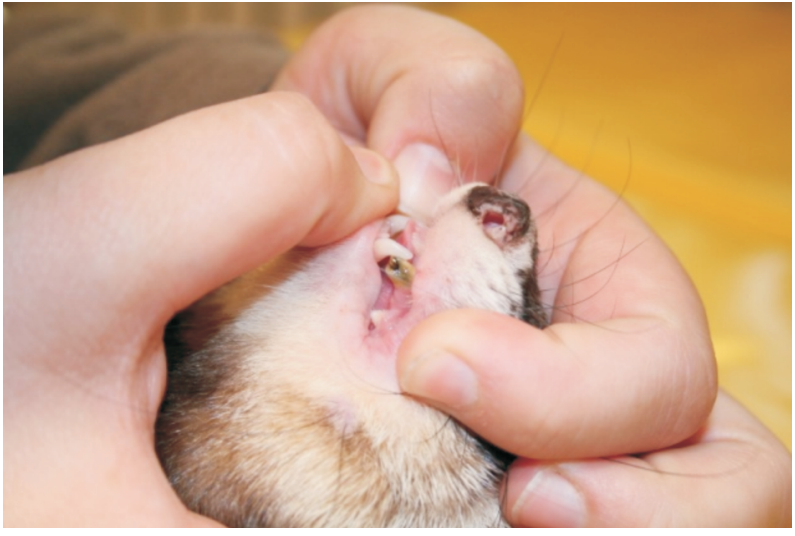

Fig. 6. Photograph taken after over $2^{1} / 2$ years of observation, showing a worn off metal post, almost to the original tissues of the tooth

\section{References}

Barańska-Gachowska M (2004) Endodoncja wieku rozwojowego i dojrzałego. Czelej Publishing.

Bargholz C, Hoer D, Zirkel Ch (2007) Endodontics. Elsevier, Urban and Partner.

Bellows J (2004) Small animals dental equipment, materials and techniques. 1st. ed., Ames IO: Blackwell.

Stein KE, Manfra MS, Siegel A, Vitoux J (2004) Comparison of hand-instrumented, heated gutta-percha and engine-driven, cold gutta-percha endodontic techniques. J Vet Dent 21: 136-145.

Tutt C (2006) Small Animal Dentistry - A Manual of Techniques. Blackwell Publishing, Ames, Iowa.

Wiggs RB (1991) Endodontic instrumentation. J Vet Dent 8: 4-10. 